\title{
O Processo Civil Pragmático E O CONSTITUCIONALISMO DiALÓGICO: Pressupostos PARA UMA Discussão SOBRE ATIVISMO JUDICIAL
}

\author{
GUSTAVO RABAY GUERRA ${ }^{\dagger}$ \\ LuIZ MESQUita de ALMEIDA NETO ${ }^{\dagger \dagger}$ \\ HENRIQUE JERÔNIMO BEZERRA MARCOS ${ }^{\dagger \dagger \dagger}$
}

RESUMO: O presente artigo propõe o estudo do Processo Civil Pragmático dentro da realidade apresentada pelo Novo Código de Processo Civil (Lei no 13.105/15). Desta forma, busca estudar o tema do direito processual em cotejo com a escola filosófica conhecida como Pragmatismo Jurídico, lidando com as consequências desta aproximação conceitual. Para tanto, realiza um estudo introdutório sobre o Pragmatismo Filosófico, evidenciando aspectos elementares desta escola filosófica, e sobre o Pragmatismo Jurídico, tratando de temas relacionados a esta outra escola eminentemente jurídica, como a análise econômica do Direito e o ativismo jurídico, especialmente com base na obra de Richard A. Posner. Depois disso, passa a analisar, propriamente, as repercussões do Pragmatismo Jurídico na esfera processual, especificamente focalizando a função dos precedentes neste novo paradigma. Há também explanação acerca do amicus curiae enquanto

\footnotetext{
† Professor do Centro de Ciências Jurídicas da Universidade Federal da Paraíba (UFPB), Doutor em Direito, Estado e Constituição pela Universidade de Brasília (UnB), Mestre em Direito Público pela Universidade Federal de Pernambuco (UFPE) e Advogado. E-mail: gustavorabay@gmail.com.

${ }^{\dagger}$ Bacharel em Direito pela Universidade Estadual da Paraíba (UEPB), Especialista em Direito Civil e Empresarial pela Universidade Damásio Educacional, Mestrando no Programa de Pós-Graduação stricto sensu em Ciências Jurídicas da Universidade Federal da Paraíba (UFPB), na Área de Concentração em Direito Econômico, Advogado e Consultor Jurídico. E-mail: luiz.dealmeidaneto@hotmail.com.

${ }^{\dagger \dagger}$ Mestrando em Ciências Jurídicas, Área de Concentração em Direitos Humanos, da Universidade Federal da Paraíba (UFPB) e Advogado. E-mail: henriquemarcos5@gmail.com.
} 
fenômeno associado ao empirismo típico da escola pragmática. Em seguida, trata do processo civil pragmático em face do constitucionalismo dialógico. Neste ponto, o artigo conclui pelo avanço do pragmatismo jurídico no Direito Processual Civil brasileiro, e tece considerações sobre seus impactos e possibilidades, particularmente associados à construção de uma cultura de diálogo no processo de tomada de decisões, baseada, por exemplo, na obra de Richard Rorty, o que associa as considerações finais deste trabalho ao referencial teórico do constitucionalismo dialógico.

Palavras-Chave: Teoria Constitucional; Novo Código de Processo Civil Brasileiro; Pragmatismo Jurídico. 
ABSTRACT: This text proposes the study of the Pragmatic Civil Procedure within the reality presented by the Brazilian New Civil Procedure Code (Act No. 13.105/15). Thereby, it carries out an introductory study on Philosophical Pragmatism, evidencing elementary aspects of this philosophical school, and on Legal Pragmatism, dealing with themes related to this eminently legal school, such as the Economic Analysis of Law and judicial activism based, especially, on Richard A. Posner's work. Thereafter, it begins to analyze the repercussions of Legal Pragmatism in Brazilian Civil Procedure, focusing on the role of precedents in this new paradigm. There is also an explanation about the amicus curiae as a phenomenon associated with the typical empiricism of the pragmatic school. Then, the article approaches to the Pragmatic Civil Procedure facing the dialogical constitutionalism. Herein, it claims the increase of legal pragmatism in Brazilian Civil Procedure, and discusses its impacts and possibilities, particularly associated to the construction of a culture of dialogue in the decision-making process, based, for example, on the work of Richard Rorty, which associates the final considerations of this work with the theoretical framework of dialogical constitutionalism.

KeYWORDS: Constitutional Theory; Brazilian New Civil Procedure Code; Legal Pragmatism. 


\section{SUMÁRIO:}

I. INTRODUÇão......................................................................................653

II. Do Pragmatismo Filosófico ao Pragmatismo Jurídico......654

III. O Pragmatismo JuRídico E SUAS RePERCUSSÕES NA ESFERA PROCESSUAL .....................................................................659

1. Precedentes no Novo Código de Processo Civil....................659

2. Amicus Curiae...............................................................................665

IV. O Processo Civil Pragmático E O CONSTITUCIONALISMO DiALÓGICO............................................667

V. CONCLUSÃO ..................................................................................671

VI. REFERÊNCIAS...........................................................................................672

\section{TABLE OF CONTENTS:}

I. INTRODUCTION ..................................................................................653

II. From Philosophical Pragmatism to Legal Pragmatism...654

III. The Legal Pragmatism AND ITS REPERCUSSIONS ON THE PROCEDURAL SPHERE ...........................................................659

1. Precedents in the Brazilian New Civil Procedure Code ....659

2. Amicus Curiae..............................................................................665

IV. The Pragmatic Civil Procedure AND DIALOGICAL CONSTITUTIONALISM ............................................667

V. CONCLUSION .......................................................................................671

VI. REFERENCES ...............................................................................................672 


\section{INTRODUÇÃO}

Em que pese a controvérsia desta afirmação, muitos entendem que a maior contribuição dos Estados Unidos da América para a filosofia foi através do desenvolvimento da Escola do Pragmatismo. Com efeito, poucas escolas filosóficas simbolizam melhor o espírito moderno como a frieza calculista do Pragmatismo; trata-se da industrialização do pensamento filosófico, da transformação do pensar em uma commodity, um bem com valor diretamente relacionado à sua efetividade e aplicação prática.

Não existe nada que traduza melhor o pensamento do homem moderno que o adagio basilar adotado pelos Pragmatistas: uma ideia (da mesma forma que uma ferramenta) só "presta" se seus efeitos práticos forem bons e bom é aquilo que é útil. Neste diapasão, o Pragmatismo Filosófico contamina o pensamento jurídico e o imbui com seus ideais de tornar-se uma ciência do prático, do objetivo e do eficaz. Hoje, pode-se afirmar que uma das vertentes mais influentes do pensamento jurídico contemporâneo é o Pragmatismo Jurídico.

Ademais, é de se mencionar que esta escola de pensamento jurídico não encerra suas ramificações na Teoria Constitucional ou na Metodologia Jurídica. Não, o Pragmatismo Jurídico é Pragmático! A redundância se justifica porque, diferentemente de tantas outras construções jurídicas que não atingem repercussões além da teoria, o Pragmatismo Jurídico é responsável por afetar a prática forense nas mais diversas áreas do Direito.

Dentre as disciplinas jurídicas afetadas, destacamos o Direito Processual Civil; tema que, em terras brasileiras, sofreu recentemente uma grande reformulação a partir da entrada em vigor do Novo Código de Processo Civil (Lei n⿳0 13.105/15).

Neste sentido, no presente trabalho, tem-se como objetivo analisar os Pragmatismos Filosófico e Jurídico e, mais especificamente, suas repercussões no Processo Civil brasileiro. Com isto, busca-se examinar quais são as atuais manifestações da mencionada corrente filosófica no Direito Processual Civil e, com esta análise, concluir se é possível afirmar que temos, hoje, um "Processo Civil Pragmático". Para alcançar este objetivo, a metodologia utilizada será a indutiva, a partir da coleta de dados por meio de pesquisa bibliográfica, eminentemente através da análise normativa e doutrina especializada.

A justificativa para a realização deste estudo transparece em razão da relevância e da atualidade do tema. O Direito Processual Civil é, sem dúvidas, uma das áreas mais importantes no estudo do Direito. Afinal, independentemente do Direito Material a ser aplicado, no caso concreto, 
é preciso domínio das regras processuais.

Ademais, é de se mencionar, inclusive, que, ainda que estejamos diante de áreas do Direito com seu próprio regramento processual (exemplo: Direito Penal com o Direito Processual Penal), não se pode olvidar de que as regras do Processo Civil possuem aplicação subsidiária e suas normas funcionam como cláusulas gerais que norteiam a aplicação de todo o Direito brasileiro. Trata-se de um verdadeiro tronco comum, de onde surgem diversas aplicações e repercussões nos mais variados ramos jurídicos.

\section{Do Pragmatismo Filosófico ao Pragmatismo Jurídico}

De acordo com o dicionário, pragmático é aquilo "[...] suscetível de aplicações práticas; voltado para a ação".$^{1}$ Em sentido semelhante, no vernáculo popular se diz pragmática a pessoa prática, realista, objetiva, um "homem de ação", em contraponto ao "filósofo" que se perde em seus devaneios. Não se pode dizer que esta inferência vulgar está completamente incorreta. Ora, o Pragmatismo, como escola filosófica, surge com fim de distanciar do filósofo o papel de "idólatra do fútil", tornando esta atividade algo mais instrumentalizável.

Dito de forma menos incisiva, para os pragmatistas, a função da filosofia é a de encontrar aplicações práticas para fórmulas abstratas; teorias devem ser enxergadas como instrumentos, não como respostas para enigmas. Desta feita, o Pragmatismo rejeita a ideia de buscar a realidade através do exame da essência dos objetos - abandona-se a empreitada Tomista de encontrar a verdade das coisas em si - para passar a buscar a verdade nas aplicações práticas dos objetos. ${ }^{2}$

Neste diapasão, William James - um dos fundadores da escola do Pragmatismo - chega a afirmar que uma ideia será verdadeira se e quando aquela ideia for boa. $\mathrm{O}$ pensador afirma categoricamente que, para ele, a existência de Deus é provada a partir da concepção de que sua existência é boa. De acordo com as próprias palavras do pensador proferidas em conferência a respeito do tema:

O único critério de verdade provável é aquele que melhor sirva para nos

${ }^{1}$ BUARQUE DE HOLLANDA, Aurélio. Novo Dicionário Aurélio da Língua

Portuguesa. $2^{\mathrm{a}}$ ed. Rio de Janeiro, RJ: Editora Nova Fronteira, 1986, p. 1377.

${ }^{2}$ RUSSELL, Bertrand. The History of Western Philosophy. New York, NY:

Touchstone Book, 1972, p. 816. 
orientar, que melhor se adapte à vida e se combine com o conjunto das exigências da experiência sem nada deixar de fora. Se as idéias teológicas satisfazem tais requisitos, se a idéia de Deus particularmente pode provar tudo isso, como negaria o pragmatismo a existência de Deus? Não teria sentido recusar a veracidade de uma idéia tão vantajosa pragmaticamente. ${ }^{3}$

Desnecessário mencionar que estes posicionamentos foram duramente criticados. Um de seus maiores oponentes, Bertrand Russell menciona que, ao seu ver, a utilidade de uma ideia ou objeto não teria epistemologicamente relação direta com o fato daquilo ser a verdade ou ser bom. ${ }^{4}$ Além disso, vale mencionar a dificuldade em se conceituar o que seria o "bom".

Apesar das críticas, a ideia do Pragmatismo firmou raízes; a noção de que o sentido de uma ideia corresponde ao conjunto de seus desdobramentos práticos é, sem dúvidas, muito atraente. Deste modo, seguindo o norte estabelecido por William James, John Dewey se destaca como um dos principais expoentes do Pragmatismo Filosófico. Semelhante ao que se tinha até então, para Dewey, a filosofia não deve se preocupar com a verdade absoluta, mas com o processo de verificação da verdade por trás das coisas. ${ }^{5}$

Efetivamente, para Dewey, a busca de verdades permanentes baseadas em conhecimentos seguros e imutáveis é uma atividade inútil; a verdade está sempre em mutação. A estrutura da verdade não é fornecida pela "filosofia crua", haja vista que esta se perde em busca de objetividade além da prática. Neste sentido, entende-se que Dewey tinha por objetivo modificar o papel que a filosofia deu a si mesma; desejava que o estudo filosófico abandonasse o papel de investigador das pretensões à verdade, e se transformasse em uma ferramenta para desenvolvimento do bem-estar da humanidade. ${ }^{6}$

Com esta sucinta introdução, foi possível introduzir o leitor ao que é o Pragmatismo filosófico. Em suma, é a escola da filosofia que pretende verificar afirmações apenas através de suas consequências práticas e sobre os interesses da humanidade. Ocorre que, aqui, se trata de um

${ }^{3}$ Cf. CABALLERO, Alexandre. A Filosofia através dos Textos. $2^{\underline{a}}$ ed. São Paulo, SP:

Editora Cultrix, 1972, p. 254.

${ }^{4}$ RUSSELL, Bertrand. The History of Western Philosophy. New York, NY:

Touchstone Book, 1972, p. 817.

${ }^{5}$ RUSSELL, Bertrand. The History of Western Philosophy. New York, NY:

Touchstone Book, 1972, p. 826.

${ }^{6}$ OLIVER, Martyn. The Hamlyn History of Philosophy. London: Hamlyn, 1999, p. 138.

3 JOURNAL OF INSTITUTIONAL STUDIES 1 (2017) 
trabalho jurídico e, sendo assim, interessa mais adentrar nas repercussões jurídicas do Pragmatismo Filosófico. Passa-se, portanto, para o estudo do Pragmatismo Jurídico.

Pode-se afirmar que o Pragmatismo Jurídico pretende explicar e apreender o elemento jurídico a partir da práxis em sua fenomenologia no meio social. Dito de outra forma: o Pragmatismo Jurídico quer aplicar o que aprendemos no Pragmatismo Filosófico ao Direito.

É de se mencionar que o Pragmatismo Jurídico obtém grande sucesso ao longo do Século XX, sendo umas das vertentes mais influentes do pensamento jurídico contemporâneo. Ilusório é imaginar, contudo, que o percurso histórico de tal escola filosófica se deu sem percalços. Com efeito, tantos são os adeptos do pragmatismo jurídico (entusiastas de suas possibilidades para a realização efetiva do Direito), quantos são os seus críticos (preocupados com as implicações possíveis, oriundas ora de uma postura quase iconoclasta da ordem jurídica sublimada pelo preceito de legalidade, ora da falta de legitimação do intérprete que adota referida postura). ${ }^{7}$

Em grande parte, o número surpreendente de críticos à esta escola de filosofia jurídica se deve ao êxito que esta construção logrou, sobretudo a partir da segunda metade do Século XX. O pragmatismo jurídico possui, em Richard A. Posner, um de seus grandes referenciais teóricos ${ }^{8}$ e, na análise econômica do Direito, um de seus grandes temas.

Não cabe, aqui, enfrentar a miúde temática da Análise Econômica do Direito (Law \& Economics), porém, em pensamento sucinto, cabe apenas aduzir que, ao longo do Século XX (em especial a partir da Década de 60, com Coase e o seu teorema, e a partir da Década de 70 com o já supracitado autor), o pragmatismo passou a veicular proposições sedutoras e pretensamente cientificistas de um índice epistemológico para o Direito, que previa que a análise empírica dos efeitos econômicos das mais diversas medidas jurídicas (fossem normas gerais e abstratas, fossem decisões concretas) deveria servir como parâmetro de racionalidade para o sistema. Especialmente atrelada a uma visão liberalista de mercado - mas não limitada a esta -, a escola filosófica tratada ganhou fôlego, e muitos de seus postulados serviram de base para

${ }^{7}$ Cf. WALDRON, Jeremy. A Dignidade da Legislação. Trad. Luís Carlos Borges. São Paulo, SP: Martins Fontes, 2003; e ELY, John Hart. Democracia e Desconfiança: Uma Teoria do Controle Judicial de Constitucionalidade. Trad. Juliana Lemos. São Paulo, SP: WMF Martins Fontes, 2010.

${ }^{8}$ Cf. POSNER, Richard. Fronteiras da Teoria do Direito. Trad. Evandro Ferreira e Silva. São Paulo, SP: Editora WMF Martins Fontes, 2011. 
o fenômeno do ativismo judicial. ${ }^{9}$

É discutível se há relação de necessidade causa-efeito entre a adoção do pragmatismo jurídico e o ativismo judicial, mas já se disse, em algumas oportunidades, que o juízo de ponderação (ainda denominado de balancing, isto é, "juízo de balanço") que, no mais das vezes, constitui o cerne da postura do intérprete no caso do ativismo judicial representaria exatamente a articulação lógico-doutrinária de uma visão pragmática do Direito. ${ }^{10}$

O fato é que, extrapolando inclusive as fronteiras iniciais de uma análise econômica, os intérpretes, aderindo conscientemente ou não a esta corrente jusfilosófica, têm adotado sistematicamente a postura de realizar uma ponderação, entre os interesses veiculados na lide apresentada ao Judiciário, e apresentado soluções que contemplam uma sistemática distinta da lógica de subsunção hermética da legalidade, condizente com preceitos tipicamente pragmáticos. Não é um fato novo a adoção de sistemas e métodos pragmáticos pelos tribunais de cúpula nos ordenamentos jurídicos dos mais diversos países, assim como não é novidade a aplicação de teses eminentemente pragmáticas (no sentido mais estrito e relacionado com a vertente filosófica ora tratada) nos tribunais de cúpula brasileiros. ${ }^{11}$

${ }_{9}^{9}$ Neste sentido, compreendemos por Ativismo Judicial a "[...] ultrapassagem das linhas demarcatórias da função jurisdicional em detrimento principalmente da função legislativa, mas, também, da função administrativa e, até mesmo, da função de governo. Não se trata do exercício desabrido da legiferação (ou de outra função não jurisdicional), que, aliás, em circunstâncias bem delimitadas, pode vir a ser deferido pela própria Constituição aos órgãos superiores do aparelho judiciário, e sim da descaracterização da função típica do Poder Judiciário com incursão insidiosa sobre o núcleo essencial de funções constitucionalmente atribuídas a outros Poderes".

RAMOS, Elival da Silva. Ativismo Judicial: Parâmetros Dogmáticos. $2^{\underline{a}}$ ed. São Paulo, SP: Saraiva, 2015, p. 129.

${ }^{10}$ WOOLHANDLER, Ann. Rethinking the Judicial Reception of Legislative Facts.

Vanderbilt Law Review, Vol. 41, 111, 1988; JARDIM, Flávio Jaime de Moraes; PAIVA, Paulo Frederico Rodrigues. Notas acerca de um Processo Civil Pragmático. Revista de Informação Legislativa, Vol. 48, 190, 2011, p. 154; e BRANCO, Paulo Gustavo Gonet. Juízo de Ponderação na Jurisdição Constitucional: Pressupostos de Fato e Teóricos Reveladores de seu Papel e de seus Limites. 2008. 383 f. Tese (Doutorado Constituição, Processo e Teoria Constitucionais, Direitos Fundamentais) - Programa de Doutorado em Direito, Universidade de Brasília, Brasília, 2008.

${ }^{11}$ D'MACÊDO, Juliana Maria. Pragmatismo Jurídico no Supremo Tribunal Federal. Direito e Humanidades, No. 25, 2013. Disponível em: 
Contudo, é de se destacar que não há relação teórica de necessidade lógica entre o juízo de ponderação, o pragmatismo e o ativismo judicial. Com efeito, é plenamente possível que o juízo de ponderação leve à conclusão de que o Judiciário deve realizar, no caso concreto, uma postura de auto contenção. Para o professor Glauco Salomão Leite, em acurada análise acerca da jurisdição constitucional, o fenômeno social da inércia legislativa (que até pode ser tratada sob o prisma de crise de representatividade no sistema político atual) ${ }^{12}$, aliado ao papel de preponderância que os mais contemporâneos sistemas de controle de constitucionalidade atribuem às cortes constitucionais, conflui para um protagonismo (talvez até excessivo) do papel do Judiciário. Este, por sua vez, pode apresentar dois comportamentos básicos, que são o ativismo judicial e a "autorrestrição estrutural" (self-restraint), que significam, a muito grosso modo, respectivamente, o alargamento dos poderes judiciais em detrimento de outras funções (geralmente, a expansão se dirige a funções tipicamente legislativas e o debate se dá no tópico de eventual vulneração da representação democrática) ou, do outro lado, a contenção do Judiciário para a atuação dos outros poderes.

O debate é muito complexo e não faz nem sentido tentar esgotá-lo nesta oportunidade. Porém, o presente trabalho se presta a tentar demonstrar como o fenômeno do pragmatismo jurídico se encontra enraizado na cultura jurídica brasileira contemporânea. Para esta finalidade, adotou-se a metodologia de abordar algumas inovações do Novo Código de Processo Civil (Lei no 13.105/2015), o "CPC/2015", enfatizando sua comparação com a filosofia típica do pragmatismo jurídico, particularmente no tocante às três principais características decorrentes da adoção de tal teoria, quais sejam: o antifundacionalismo, o consequencialismo e o contextualismo..$^{13}$

Desde já, destaca-se, até como forma de reforçar a observação que prossegue nas linhas adiante, que a maioria das inovações legislativas do Novo Código de Processo Civil aqui tratadas são, a bem da verdade, sistematização de legislações especiais que já vinham sendo adotadas frequentemente, sobretudo no âmbito dos tribunais superiores, o que permite divisar, com clareza, que o fenômeno do pragmatismo jurídico

$<$ http://seer.uscs.edu.br/index.php/revista direito/article/view/2362>. Acesso em: $27 \mathrm{de}$ julho de 2017.

${ }^{12}$ Cf. LEITE, Glauco Salomão. Inércia Legislativa e Ativismo Judicial: a Dinâmica da Separação dos Poderes na Ordem Constitucional Brasileira. Direito, Estado e

Sociedade, No. 45, 2014.

${ }_{13}$ POGREBINSCHI, Thamy. Pragmatismo: Teoria Social e Política. Rio de Janeiro, RJ: Relume Dumará, 2005, p. 25. 
na ótica do processo civil brasileiro é uma realidade em curso há bastante tempo, e que apenas se aprofunda no atual diploma processual.

\section{O PRAgMATISMO JURÍDiCO E SUAS REPERCUSSÕES NA ESFERA PROCESSUAL}

Superada a análise do Pragmatismo Filosófico e do Pragmatismo Jurídico, passam-se a tecer considerações a respeito das repercussões do pragmatismo na esfera jurídica processual brasileira. Basicamente, abordam-se duas esferas de inovações, a primeira delas relacionada à expansão de uma teoria dos precedentes no novo diploma processual, e a segunda ligada ao aprofundamento, e quase generalização, das possibilidades de presença do amicus curiae no processo judicial.

\section{Precedentes no Novo Código de Processo Civil}

Em uma ordem preliminar e básica de cogitações, o debate referente aos precedentes ${ }^{14}$ tem se pautado pelas preocupações dos pensadores sobre o fato de que originariamente a montagem do Estado de Direito se ocupava de separar uma função legislativa (que traçava e delineava os direitos e deveres em normas gerais) de uma função judicial (que resolvia tão somente o caso concreto que apresentasse uma lide). Esta construção sempre fez mais sentido para os países que adotaram o sistema conhecido como Civil Law. Para países com esta tradição jurídica, soa estranho que o Poder Judiciário possa delinear, mesmo que a partir de um caso representativo de controvérsia, linhas gerais para enfrentamento de situações futuras. É de se dizer: a prática do precedente traz, em si, boa parte da discussão atinente a uma possível usurpação de função legislativa pelo Judiciário.

Contudo, apesar de certa razão teórica assistir a quem se ressinta da prática dos precedentes, não é razoável argumentar, em sociedades

14 “Precedente é qualquer julgamento que venha a ser utilizado como fundamento de um outro julgamento que venha a ser posteriormente proferido. Dessa forma, sempre que um órgão jurisdicional se valer de uma decisão previamente proferida para fundamentar sua decisão, empregando-a como base de tal julgamento, a decisão anteriormente prolatada será considerada um precedente". NEVES, Daniel Amorim Assumpção. Manual de Direito Processual Civil: Volume Único. $8^{\underline{a}}$ ed. Salvador, BA: Juspodivm, 2016, p. 1297. 
contemporâneas (com um nível de complexidade do tecido social altíssimo, com uma quantidade de demandas - inclusive repetitivas - em profusão ${ }^{15}$ ), contra este expediente. Por outro lado, se de fato faz sentido, na atual sociedade, a existência de uma lógica de precedentes, as condições e os termos em que ela se processa e se desenvolve devem ser analisados e questionados, pois é possível que se atribuam poderes excessivos ao Judiciário, quando da formatação deste sistema.

Há, neste sentido e em boa parte dos ordenamentos jurídicos atuais, formas de se dotar os precedentes de força normativa, vinculante, ou de observância obrigatória. É tradicional a menção à construção, típica do direito de tradição anglo-saxônica, comumente denominado de Common Law, do instituto da stare decisis, vocábulo em latim que trata do respeito obrigatório ao que foi decidido no precedente.

No Direito brasileiro, é reconhecida a evolução jurídica acima tratada, consistente com o avanço de uma prática jurídica pautada por precedentes, dotando-se estes, em alguns casos, de força obrigatória. ${ }^{16}$ Geralmente, identifica-se o início de uma maior preponderância jurídica dos precedentes, no contexto da ordem jurídica brasileira, a partir da Emenda Constitucional no 45/04, que, introduzindo figuras como a súmula vinculante, possibilitou uma valorização da cultura de relevância de decisões do órgão jurisdicional, em virtude de sua aptidão para repercutir em casos futuros. A tendência se seguiu nos anos seguintes e, por exemplo, a partir da Lei no 11.418/06 - que regulamentou o art. 102, \$3을 da Constituição da República (dispositivo este incluído pela EC 45/04) e alterou substancialmente o anterior Código de Processo Civil de 1973 - os processos perante os tribunais de cúpula (notadamente STF e STJ) passaram a ter dinâmica totalmente diversa do que se via até tal momento.

Ali então já se falava da "repercussão geral", figura que atrelava a atividade destes tribunais não mais apenas à discussão jurídica em comento no processo judicial, mas à relevância - e à repercussão, daí o nome - da questão suscitada para a sociedade: critério este que se revelaria extremamente subjetivo, e uma verdadeira cláusula geral que

${ }^{15}$ Cf. ADEODATO, João Maurício. Ética e Retórica: para uma Teoria da Dogmática Jurídica. 5aㅡ ed. São Paulo, SP: Editora Saraiva, 2012.

${ }^{16}$ Cf. DONIZETTI, Elpídio. A Força dos Precedentes no Novo Código de Processo Civil. 2014. Disponível em:

<http://www9.tjmg.jus.br/data/files/7B/96/D0/66/2BCCB4109195A3B4E81808A8/A\%20f orca $\% 20$ dos $\% 20$ precedentes $\% 20$ no $\% 20$ novo $\% 20$ Codigo $\% 20 \mathrm{de} \% 20$ Processo $\% 20$ Civil.p df $>$. Acesso em: 26 de julho de 2017.

3 JOURNAL OF INSTITUTIONAL STUDIES 1 (2017) 
viria a permitir um crivo político da seleção de processos a serem julgados, pela análise da sua aptidão para gerar efeitos na sociedade ou na ordem jurídica como um todo. A ausência de repercussão geral passa a ser passível de não conhecimento do recurso extraordinário, de acordo com o art. 543-A, do Código de Processo Civil de 1973 (Lei no 5.869/73, deste ponto em diante designado como "CPC/1973"), que fora justamente acrescentado pela Lei $\mathrm{n}^{\mathrm{o}} 11.418 / 06$, como já dito em regulamentação ao art. 102, §3ㅜㅡ, da Constituição da República. Além do mais, na mesma ocasião, a própria Lei $\mathrm{n}^{\mathrm{o}}$ 11.418/06 acrescentou também o art. 543-B, no CPC/1973, para prever a possibilidade da fixação do recurso representativo de controvérsia, que vinculava a apreciação de recursos em todo o país em virtude da seleção realizada a partir do critério de identidade com um caso destacado pelo tribunal superior.

No mesmo espírito, mas aí já com a edição da Lei $\mathrm{n}^{\mathrm{0}}$ 11.672/08, ainda se adicionou o art. 543-C ao CPC/1973, que previa a figura dos recursos repetitivos no âmbito do STJ. A grande distinção era a possibilidade de reprodução automática do precedente do tribunal superior (art. 543-C, $\S 7^{\circ}, C P C / 1973$, que representava importante avanço em relação ao tímido art. 543-B, §3으. CPC/1973).

Contudo, a prática demonstrou que ambos os tribunais (tanto o STF, quanto o STJ) passaram a utilizar o instituto dos recursos repetitivos. Todas estas tendências foram incorporadas e potencializadas no Código de Processo Civil atual, que, sobretudo em seus arts. 1.036 a 1.041, CPC/2015, inclusive solucionando qualquer possível incompatibilidade entre o recurso extraordinário e o recurso repetitivo, ou sobre a previsão legal de recursos repetitivos e as atribuições do STF, dispõe sobre "julgamento dos recursos extraordinário e especial repetitivos", de onde se extrai o seguinte:

Merece destaque inicial que, no novo $\mathrm{CPC}$, não só o recurso especial mas também o recurso extraordinário passa a receber disciplina de recurso repetitivo. É inegável, assim, o avanço do novo CPC em relação à disciplina do art. 543-B do CPC atual que, em rigor, não admite o processamento e o julgamento de recursos extraordinários repetitivos, mas, menos que isso, apenas a discussão sobre recursos extraordinários múltiplos apresentarem, ou não, repercussão geral. Ademais, é inegável que o art. 543-C do CPC atual limita-se à disciplina dos recursos especiais (grifo no original) repetitivos, não obstante a prática do STF ter consagrado também o processamento dos extraordinários como repetitivos. De qualquer sorte, o novo $\mathrm{CPC}$ coloca fim a quaisquer discussões que, no âmbito do CPC atual, poderiam ser desenvolvidas a partir dessa constatação, como a leitura do caput do art. 1.036 
do novo CPC evidencia. ${ }^{17}$

Juntamente a esta cultura dos precedentes (e, na verdade, associados a essa cultura), adotam-se, no Judiciário brasileiro, dois temas muito interessantes que colaboram para o aumento do papel do Judiciário e para o surgimento do fenômeno conhecido em doutrina como "ativismo judicial". São eles o distinguishing e o overruling. Ambos são conceitos chave para compreender a operacionalização do paradigma extraído do precedente judicial, obtido por meio de instrumentos como a súmula vinculante ou o recurso repetitivo (eminentemente, os arts. 926, 927 e 928 do CPC/2015).

Primeiramente, o distinguishing é uma técnica de cotejo entre o precedente, paradigmático, e o caso concreto. ${ }^{18} \mathrm{O}$ julgador pode, assim, trabalhando nas causas e condições do caso fático que está analisando, concluir que este se amolda, ou não, ao paradigma que foi construído, explicitando as razões pelas quais entende que a situação é diversa, ou peculiar, e justificando o motivo pelo qual, naquele caso, entende, por exemplo, que o precedente não é aplicável. No CPC/2015, o diploma processual explicitou o instituto, nos termos do art. 489, §1 ${ }^{\circ}$, V e VI, CPC/2015. Em comentário a tal questão, já se disse o seguinte:

Os precedentes vinculantes não devem ser aplicados de qualquer maneira pelos magistrados. Há necessidade de que seja realizada uma comparação entre o caso concreto e a ratio decidendi da decisão paradigmática. (...). Se não houver coincidência entre os fatos discutidos na demanda e a tese jurídica que subsidiou o precedente, ou, ainda, se houver alguma peculiaridade no caso que afaste a aplicação da ratio decidendi daquele precedente, o magistrado poderá se ater à hipótese sub judice sem se vincular ao julgamento anterior. ${ }^{19}$

Na própria dinâmica dos recursos repetitivos, o distinguishing (ou

${ }_{17}$ BUENO, Cassio Scarpinella. Novo Código de Processo Civil Anotado. São Paulo, SP: Editora Saraiva, 2015, p. 675.

${ }^{18}$ Sobre a realidade do tema na prática judicial brasileira, cf. GARCIA, André Luis

Bitar de Lima; REI, José Anijar Fragoso. O Distinguishing Realizado pelo STF no Julgamento da ADIN 3.421-PR. Revista de Informação Legislativa, Vol. 49, 196, 2012. ${ }^{19}$ DONIZETTI, Elpídio. A Força dos Precedentes no Novo Código de Processo Civil. 2014, p. 4-5. Disponível em:

<http://www9.tjmg.jus.br/data/files/7B/96/D0/66/2BCCB4109195A3B4E81808A8/A\%20f orca $\% 20 \mathrm{dos} \% 20$ precedentes $\% 20$ no $\% 20$ novo $\% 20$ Codigo $\% 20 \mathrm{de} \% 20$ Processo $\% 20$ Civil.p df $>$. Acesso em: 26 de julho de 2017.

3 JOURNAL OF INSTITUTIONAL STUDIES 1 (2017) 
distinção, como ficou ali consagrado) é contemplado, entre os $\S \S 9^{\circ}$ e 13 , do art. 1.037, CPC/2015, que, em geral, trata do processamento dos recursos repetitivos nos tribunais superiores.

Já o overruling consiste na possibilidade de superação do precedente criado, inclusive, pela própria autoridade que o editou. Pode-se dizer que este instituto trata da revogação do entendimento anterior, por diversos motivos, entre os quais se destacam:

Por meio dessa técnica (overruling), o precedente é revogado ou superado em razão da modificação dos valores sociais, dos conceitos jurídicos, da tecnologia ou mesmo em virtude de erro gerador de instabilidade em sua aplicação. $\mathrm{O}$ paradigma escolhido se aplicaria ao caso sob julgamento, contudo, em face desses fatores, não há conveniência na preservação do precedente. ${ }^{20}$

De uma maneira geral, a tradição norte-americana, conhecida como Common Law, permite o que se denomina de overruling incidental (ou, ainda, o anticipatory overruling), que significa que qualquer juiz possa, no caso submetido a seu crivo, analisar se houve superação do precedente, notadamente, quando há forte alteração no estado de coisas (como na alteração legislativa da norma que funcionou como razão de decidir no precedente, etc.). No Brasil, também se fala na hipótese expressa de o tribunal que editou o precedente superá-lo, ele próprio. A possibilidade, aliás, já existe desde a edição da normatização referente à Súmula Vinculante, onde o art. 3ㅜㅡ, da Lei no 11.417/06, previa ação específica, com a finalidade de revisar ou cancelar súmula vinculante anteriormente aprovada.

Portanto, o que se tem, no Brasil, é que o Novo Código de Processo Civil aprofunda uma cultura enraizada de precedentes, que já vinha em curso antes de sua edição, e este tema é particularmente relevante neste estudo porque representa forte influência do pragmatismo jurídico à prática processual brasileira. Como já se disse, em outra oportunidade, os vetores que caracterizam o pragmatismo são, basicamente, três: o antifundacionalismo, o consequencialismo e o contextualismo. ${ }^{21}$

A própria adoção de uma teoria dos precedentes permite a visão

${ }^{20}$ DONIZETTI, Elpídio. A Força dos Precedentes no Novo Código de Processo Civil. 2014, p. 4-5. Disponível em:

<http://www9.tjmg.jus.br/data/files/7B/96/D0/66/2BCCB4109195A3B4E81808A8/A\%20f orca $\% 20$ dos $\% 20$ precedentes $\% 20$ no $\% 20$ novo $\% 20$ Codigo $\% 20$ de $\% 20$ Processo $\% 20$ Civil.p $\underline{\mathrm{df}}>$. Acesso em: 26 de julho de 2017.

${ }^{21}$ POGREBINSCHI, Thamy. Pragmatismo: Teoria Social e Política. Rio de Janeiro, RJ: Relume Dumará, 2005, p. 25. 
antifundacionalista do Estado de Direito, pois representa uma superação dos tradicionais papéis dos poderes (ou funções) do Estado. Com efeito, originalmente se tinha o pronunciamento genérico e abstrato a cargo do Poder Legislativo, ao passo em que ao Judiciário cabia a solução dos casos concretos de litígios pontuais. A atuação do Judiciário de forma genérica, abstrata e construindo paradigmas de atuação para casos futuros, decerto, representa uma alteração de sua função original, o que só é possível no desapego, no antifundacionalismo, em relação à concepção original de Estado.

Outrossim, nos termos do desenvolvimento de Antonio Moreira Maués, ${ }^{22}$ os precedentes apresentam-se a partir de três modelos: precedentes como princípios, como regras e como analogias. ${ }^{23}$ Nesta senda, o sistema adotado pelo CPC/2015 pode ser compreendido como antifundacionalista em razão das disposições processuais da normativa atribuírem força cogente à observância dos precedentes judiciais, fazendo com que estes se aproximem da lógica do precedente como regra (afastando-se, de igual modo, da ideia de precedente como princípio). Não obstante, é preciso destacar que, apesar do predomínio do precedente cogente, a possibilidade de distinguishing autoriza a conclusão de que o atual Código de Processo Civil, também, adota o primado do precedente como analogia. Sendo assim, o fortalecimento destes dois modelos (precedentes como regras e precedentes como analogias) possibilita a conclusão de que o CPC/2015 se afasta dos precedentes como princípios e, necessariamente, enfraquece a dialógica de fundamentação nas decisões judiciais derivadas, se individualmente consideradas. Em razão deste enfraquecimento, tem-se $\mathrm{o}$ antifundacionalismo dos precedentes sob a égide do novo Código.

Por outro lado, não se pode ignorar que toda a função judicante que se molda na teoria dos precedentes é essencialmente contextualista, pois, em maioria, tais construções se pautam por condições e contornos de casos práticos de litígio, que dão o tom da decisão judicial paradigmática, e, posteriormente, vinculam a aplicação das teses. O próprio instituto do distinguishing é um elemento icônico da dinâmica contextual que envolve o ordenamento jurídico com base em precedentes. A análise do contexto

${ }^{22}$ MAUÉS, Antonio Moreira. Jogando com os Precedentes: Regras, Analogias,

Princípios. Revista Direito GV, Vol. 8, 2, 2012. Disponível em:

$<$ http://direitosp.fgv.br/sites/direitosp.fgv.br/files/artigo-Edicao-revista/09 rev16 587-

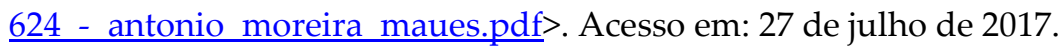

${ }^{23}$ A respeito do desenvolvimento da ideia dos precedentes como regras, cf. SCHAUER, Frederick. Playing by the Rules: a Philosophical Examination of Rule-Based

Decision-Making in Law and in Life. Oxford: Clarendon Press, 2002, p. 77 e ss. 
(seja ele jurídico, fático, social, moral, etc.) sobreleva-se na análise acerca da aplicação, superação ou inadequação do precedente ao caso prático, como se viu acima.

Seguindo esta lógica, o consequencialismo é tanto o início quanto o fim da aplicação do pragmatismo que marca tão definitivamente a teoria dos precedentes. Como origem, temos que são justamente as consequências que tornam admissível a adoção de uma teoria dos precedentes. Neste ponto, vemos que a quantidade, a especialização e o dinamismo das relações sociais dificultam (para não dizer que impossibilitam) a atuação do Judiciário, que deveria, em uma visão tradicional, analisar e solucionar individualmente cada caso. $\mathrm{O}$ número de casos é, abertamente, a justificativa da legislação para a adoção de teses de paradigma. Por outro lado, a relevância dos casos continua a ser a legitimação da atuação através de conceitos como a repercussão geral.

Seja como for, pela comparação dos institutos apresentados aos vetores que marcam o pragmatismo jurídico, percebe-se que este possui um núcleo muito atuante na lógica dos precedentes, especialmente nos países de tradição romano-germânica, da Civil Law, onde a sua aplicação corresponde a uma miscigenação de conceitos difusos, resultando em uma forte presença dos elementos de antifundacionalismo, contextualismo e consequencialismo, como acima se expôs.

\section{Amicus Curiae}

Por último, destaca-se, ainda, a crescente e forte presença do empirismo - fonte metodológica tradicional do pragmatismo, com ligação forte ao consequencialismo que rege esta doutrina - na lógica processual brasileira, com especial referência à figura do amicus curiae. Tal instituto se refere à possibilidade de admissão de um terceiro, geralmente especializado em determinada área do conhecimento, para auxiliar na instrução do processo ou, até mesmo, na discussão jurídica. Nos casos em que se demanda um conhecimento mais específico de determinado tema (como nas matérias que são mais diretamente de ordem econômica, aquelas que tratam do meio ambiente, etc.), admite-se o ingresso de um terceiro desinteressado - diz-se desinteressado porque ele não assume nenhuma posição subjetiva entre as partes no processo - que atua apenas provendo conhecimentos empíricos sobre os fatos de que tenha conhecimento, ou até dados jurídicos mais específicos.

Os antecedentes históricos, no ordenamento jurídico brasileiro, podem ser vistos desde o art. 32, da Lei no $4.726 / 65$, em que, no âmbito da Junta Comercial, era possível, em assuntos jurídicos, oficiar a 
especialistas na área do comércio. Já o art. 31, da Lei no 6.385/76, incluído pela Lei $n^{\circ} 6.616 / 78$, dispõe que, nos processos que envolvam assuntos da competência da Comissão de Valores Mobiliários, esta sempre seria intimada, no sentido de esclarecer a matéria fática envolvida na questão. No sistema brasileiro de defesa da concorrência, igualmente, instituído pela Lei no 12.529/11, também está prevista a participação do CADE nos processos referentes aos temas tratados naquela norma.

Contudo, a verdade é que o maior destaque para o instituto veio com a previsibilidade de participação desta figura nos processos de competência do STF, através de normas como a Lei nº 9.868/99, que trata das Ações Declaratórias de Constitucionalidade (ADC) e das Ações Diretas de Inconstitucionalidade (ADI), que previa, expressamente, no seu art. $7^{\circ}, \$ 2^{\circ}$, que o relator admitisse a manifestação de órgão ou entidade, sobre a matéria ali discutida. A tendência seguiu e, tanto a lei que trata da Arguição de Descumprimento de Preceito Fundamental (ADPF) - Lei no 9.882/99 -, como a norma que fundamenta a edição de súmulas vinculantes - Lei $n^{-}$11.417/06 -, sempre trouxeram a figura do amicus curiae em seus textos.

O novo diploma processual, neste ponto também, aprofunda e generaliza o instituto, passando a admitir a presença (ou pelo menos a previsão, em abstrato, da possibilidade da presença) do amicus curiae em todos os processos da órbita civil, com fundamento no art. 138, CPC/2015.24 Esta realidade condiz, em muito, com o pragmatismo jurídico, porque permite, e até valoriza, a participação de profissionais e especialistas sobre a matéria fática que se está avaliando, no ponto de empirismo e de observação prática que marca esta corrente jusfilosófica. $\mathrm{Na}$ verdade, a proximidade entre o instituto e a análise econômica do Direito é óbvia, pois esta trata, justamente, da análise por pessoas capacitadas em economia das medidas que o ordenamento jurídico veicula. Provavelmente, na ordem jurídica processual brasileira, o instrumento através do qual se daria tal análise, pragmática e econômica, de peritos e analistas econômicos, seria, no mais das vezes, o amicus curiae. Sobre este ponto, interessante o esclarecimento de Richard Posner:

(...), o trabalho do economista no que se refere às políticas e práticas acerca do interesse público, tanto as vigentes quanto aquelas que se propõem, consiste essencialmente em advertir-nos sobre as consequências que os não

24 TALAMINI, Eduardo. Amicus Curiae no CPC/2015: Amicus curiae - comentários ao art. 138 do CPC. In: Teresa Arruda Alvim Wambier; Fredie Didier Jr.; Eduardo Talamini; Bruno Dantas (Orgs.). Breves Comentários ao Novo Código de Processo Civil. São Paulo, SP: Editora Revista dos Tribunais, 2015. 
economistas tendem a negligenciar e que frequentemente, embora nem sempre, são adversas ou no mínimo onerosas. Essa aplicação da economia deve ser bem-vinda pelos advogados que julguem importante descobrir quais são as consequências reais das doutrinas e instituições jurídicas, inclusive aquelas que os profissionais do direito consideram intocáveis. ${ }^{25}$

Desta forma, verifica-se a conexão entre o instituto do amicus curiae, previsto no art. 318, CPC/2015, e uma possível análise econômica do Direito, bem como sua aptidão em confluir para uma visão mais pragmática do processo. Todos os institutos abordados neste tópico, aliás, montam um cenário que permite divisar que os poderes do juiz serão mais consistentes no que se chama de case management ${ }^{26}$, onde se reflete uma visão mais gerencial dos conflitos sociais trazidos ao Judiciário, bem como uma noção mais pragmática e naturalmente empirista, que permite ao julgador tratar o caso cada vez mais a partir dos efeitos que sua sentença, ou seu pronunciamento, causariam à sociedade, ao invés das preocupações tradicionais, pautadas pela verificação daquilo que o legislador (utopicamente, o representante do povo) houvesse previsto.

\section{O Processo Civil Pragmático e o CONSTITUCiONALISMo Dialógico}

Todas estas transformações, ocorridas na teoria do Direito, especialmente no tocante à esfera processual, têm feito com que alguns autores contemporâneos tratem do que se tem comumente designado de "processo civil pragmático" 27. Analisando a situação, Vicente de Paula Ataide Junior assevera que há em curso uma transição para:

25 POSNER, Richard. Fronteiras da Teoria do Direito. Trad. Evandro Ferreira e Silva. São Paulo, SP: Editora WMF Martins Fontes, 2011, p. 33.

${ }^{26}$ Sobre os poderes do juiz no Novo Código e a sua convivência com a realidade social e institucional que impõem uma visão estratégica e gerencial dos processos, cf. ARAUJO, Eduardo André Vargas de. Os Poderes do Juiz e o Novo Código de Processo Civil: Estudo sobre Case Management e Flexibilização do Processo. 2015. Disponível em: $<$ https://www.lume.ufrgs.br/bitstream/handle/10183/129816/000976401.pdf?sequence= 1>. Acesso em: 26 de julho de 2017.

${ }^{27}$ Cf. JARDIM, Flávio Jaime de Moraes; PAIVA, Paulo Frederico Rodrigues. Notas acerca de um Processo Civil Pragmático. Revista de Informação Legislativa, Vol. 48, 190, 2011.

3 JOURNAL OF INSTITUTIONAL STUDIES 1 (2017) 
[...] uma metodologia processual desligada do racionalismo, que não dependa tanto de conceitos ou de abstrações teóricas e que desincorpore do 'seu discurso qualquer forma de dogmatismo ou de autoridade'; que não fragmente o fenômeno processual a partir de visões parcializadas. Um método francamente antiformalista, que se desprenda da necessária correspondência entre as soluções processuais e o sistema construído pela ciência processual. Um método que avalie a verdade das proposições de seu campo de conhecimento através do contato com o mundo empírico. Uma metodologia do direito processual que inclua as técnicas de investigação das ciências sociais e econômicas para melhor avaliar a adoção de uma ou de outra solução. (...) O quinto estágio metodológico do direito processual - constituído a partir do pragmatismo - vem para somar forças à ruptura metodológica com o paradigma racionalista. Certamente despertará resistências, sem as quais não representaria propriamente uma mudança de paradigmas. ${ }^{28}$

Estas considerações permitem concluir que há uma tendência de adoção, crescente, do pragmatismo na ordem jurídica brasileira, especialmente com base na dinâmica processual jurídica. Porém, outra inquietação surge, quando se analisa mais detidamente a relação entre ativismo judicial e pragmatismo jurídico. A relação entre as construções já foi tratada antes neste trabalho, porém, outro ponto de contato reside no conceito de verdade para o pragmatismo.

O pragmatismo, em nenhuma de suas fases, concebeu um conceito de "verdade" muito forte - dito de outra forma, o seu antifundacionalismo sempre representou um apelo contra o essencialismo, bem como um contraponto às correntes correspondentistas e coerentistas da verdade e em muitas ocasiões foi acusado de relativismo ou de antirracionalismo (não que esta acusação fosse peremptoriamente negada, antes em alguns aspectos foi até assumida como correta pelo próprio pragmatismo)..$^{29} \mathrm{Em}$ tempos contemporâneos, contudo, sobretudo com base na obra de Rorty ${ }^{30}$, fixou-se que o princípio da conversação seria o único limite para

${ }^{28}$ ATAIDE JUNIOR, Vicente de Paula. Processo Civil Pragmático. 2013. 278 f. Tese (Doutorado em Direito das Relações Sociais) - Programa de Pós-Graduação em Direito, Universidade Federal do Paraná, Curitiba, 2013, p 46.

${ }^{29}$ Cf. POGREBINSCHI, Thamy. Pragmatismo: Teoria Social e Política. Rio de Janeiro, RJ: Relume Dumará, 2005.

${ }^{30}$ Cf. CAMPBELL, James. O Uso Rortyano de Dewey. Trad. Heraldo Aparecido Silva. Redescrições: Revista do GT Pragmatismo e Filosofia Americana, Ano 1, no 2, 2009. Disponível em: 
a investigação.

Um dos grandes problemas e inconvenientes de uma crescente noção de pragmatismo vem a ser a dificuldade de se conceber o método de ativismo judicial em vigência no Brasil, em contraponto à noção - ética e legitimadora do ordenamento jurídico, à toda evidência - de verdade. Com efeito, nota-se que o Brasil utiliza o que se convenciona chamar de Constitucionalismo forte ou centralizado, para designar que as cortes superiores possuem poderes que extrapolam a feição original do balanço entre os poderes, e permitem o protagonismo da função jurisdicional. Talvez esta visão possua alguma relevância teórica em uma teoria jurídica tradicional, onde as cortes de ápice revelavam a "verdade" disposta na legislação e, principalmente, no texto constitucional. Porém, nos campos do pragmatismo, limita a hipótese de conversação, e o diálogo institucional que, em sede de pragmatismo, tornam-se muito relevantes.

Neste cenário, o pragmatismo jurídico deve zelar, tanto quanto possível, por estruturas de poder que valorizem a articulação de diálogos institucionais, que valorizem a conversação e uma solidariedade pautada por um etnocentrismo que reconhece que, essencialmente, não há um conteúdo ético imanente e intrínseco ao ser humano. Neste sentido, temse que:

A solidariedade, em nossa opinião, é o elemento principal para alcançarmos a já comentada meta de Mill, em busca da otimização do equilíbrio entre o aumento da liberdade e a diminuição do sofrimento. Se estivermos de acordo com tal meta, podemos chegar perto dela através da imprensa livre, das universidades livres e da opinião pública esclarecida. (...). Esta é, sem dúvida, uma questão a ser abordada de diversas maneiras, nas diversas áreas de nossa cultura, como em estudos antropológicos, documentários, reportagens jornalísticas, entre outros. ${ }^{31}$

Assim o sendo, compreende-se que o incremento do Pragmatismo no Processo Civil brasileiro representa um fenômeno de implicações epistemológicas na aplicação do Direito. Afinal, a adoção de um paradigma pragmático representou para o Direito, ao longo do Século XX, uma enorme alteração epistemológica, uma vez que as ciências jurídicas eram marcadas por construções eminentemente formalistas,

$<$ http://www.gtpragmatismo.com.br/redescricoes/redescricoes/02/2Campbell.pdf $>$.

Acesso em: 26 de julho de 2017.

${ }^{31}$ GONÇALVES, Daniel Luís Cidade. O Pragmatismo de Richard Rorty e suas

Consequências Políticas. Cognitio-Estudos: Revista Eletrônica de Filosofia, Vol. 11, 2, 2014, p. 188-189.

3 JOURNAL OF INSTITUTIONAL STUDIES 1 (2017) 
pautadas por um raciocínio autorreferente, e muito baseadas em um sistema assumidamente idealizado. A obrigatoriedade da observância do Direito sempre fora extraída do conceito de soberania e a integralidade da ordem jurídica mantida com base na noção de poder (um poder soberano, que atribuía autoridade a alguns proeminentes da sociedade), também relacionada com a soberania. Para o pragmatismo, estas noções não são equivocadas (a soberania e a autoridade possuíam função relevante na ordem social), porém o critério de validade das medidas jurídicas não poderia mais ser a própria autoridade que as proferiu, ou sua adequação a um sistema pré-concebido de verificação baseado no próprio sistema (como era o caso do positivismo jurídico vigente e predominante até então), mas sim a aferição das consequências da medida jurídica adotada para a sociedade. Por tais razões, a adoção de um constitucionalismo centralizado (forte) representa um substancial limitador nos diálogos institucionais pragmáticos típicos deste referencial teórico, uma vez que a corte constitucional extrai fundamento de validade de seus pronunciamentos de sua legitimidade jurídica, e não os submete a nenhum debate posterior. ${ }^{32}$

Portanto, uma das construções que se articula nesta discussão, e pode servir de norte, vem a ser o constitucionalismo dialógico (fraco) onde o Poder Judiciário (que muitas vezes tem a última palavra, mesmo neste sistema), apesar de declarar a inconstitucionalidade de leis, por exemplo, e apesar de tomar posturas ativistas igualmente, submete sua decisão a um diálogo com o Poder Legislativo, no sentido de pautar uma reflexão sobre alguns contornos ou sobre o método de aplicação da lei, ou da decisão, geralmente com um prazo para que o Poder Legislativo atue, sob pena de intervenção, aí sim, mais direta da decisão do Poder Judiciário. São exemplos desta construção, mais comumente citados, o constitucionalismo canadense, o constitucionalismo israelense, entre outros. ${ }^{33}$

${ }^{32}$ Cf. RORTY, Richard. Consequências do Pragmatismo. Trad. João Duarte. Lisboa: Instituto Piaget, 1982; ROCHA, Maria José Pereira. A Crítica de Richard Rorty à Teoria do Conhecimento e uma Possibilidade de Redescrição. Redescrições: Revista do GT Pragmatismo e Filosofia Americana, Ano 3, 3, 2012. Disponível em: $<$ http://www.gtpragmatismo.com.br/redescricoes/redescricoes/ano3 03/artigo4.pdf $>$. Acesso em: 26 de julho de 2017; e GONÇALVES, Daniel Luís Cidade. O Pragmatismo de Richard Rorty e suas Consequências Políticas. Cognitio-Estudos: Revista Eletrônica de Filosofia, Vol. 11, 2, 2014, p. 188-189.

${ }_{33}$ Cf. TAVARES, Rodrigo de Souza; BERMAN, José Guilherme. Teorias Dialógicas e os Sistemas de Constituições Não Escritas: o Caso Israelense. Anais do XVIII Congresso 


\section{CONCLUSÃo}

Como se pode notar a partir da exposição contida neste texto, o pragmatismo jurídico tem se enraizado paulatinamente na cultura jurídica brasileira. O exame do novo diploma processual (CPC/2015), para muito além de fotografar que ali residem institutos tipicamente pragmáticos, permite analisar, em acepção histórica recente (mas muito profusa, em termos de legislação e jurisprudência), que na verdade este novo código, no tema aqui abordado, apenas representa uma expansão e um aprofundamento da adoção de um paradigma processual tipicamente pragmático - reconhecido e denominado, em recente doutrina, de "processo civil pragmático".

Se, por um lado, o sucesso de teorias e institutos pragmáticos sobreleva o papel do Judiciário, tornando-o protagonista em um ativismo que ganha mais aparato em uma postura antifundacional e consequencialista, notadamente, com pontos de conflito em relação ao Poder Legislativo, no caso brasileiro, especificamente, o conceito de "verdade" para o pragmatismo, de outro lado, pode ser um inconveniente para o sistema jurídico até então adotado.

Ocorre que a figura de uma autoridade, que detém uma legitimidade (geralmente jurídica e, como se sabe, pretensamente científica, ou de notável saber) para dar a resposta final, de maneira isolada, e para dizer o que é "certo", tem pouco, ou nenhum, fundamento na lógica (se é que ela de fato existe nesta teoria jurídica) do pragmatismo.

A evolução desta teoria permite concluir que o diálogo e a conversação são parâmetros de guia que não podem ser abandonados, por onde, em tal contexto, defende-se que a noção de um constitucionalismo forte, centralizado, com base em um processo tipicamente pragmático, é uma contradição latente.

A tendência, baseada nesta concepção eminentemente teórica, pode ser de uma profunda contradição no sistema - que pode também afetar as instituições -, o que nos leva à sugestão da adoção de formas de atuação judicial mais pautadas pelo diálogo, o que, especificamente no caso da corte constitucional, levaria, por exemplo, à construção de um modelo de constitucionalismo fraco, ou dialógico, em que a conversação entre Judiciário e Legislativo (com formas de preservação mútua das autoridades, nestes sistemas) pudesse servir à construção de uma norma que, processual e juridicamente falando, cada vez menos será a

Nacional do CONPEDI. Florianópolis, SC: Fundação Boiteux, 2011. Disponível em:

$<$ http://www.publicadireito.com.br/conpedi/manaus/arquivos/anais/sao paulo/2259.p df $>$. Acesso em: 26 de julho de 2017.

3 JOURNAL OF INSTITUTIONAL STUDIES 1 (2017) 
"verdade", e cada vez mais será, à toda evidência, aquilo que convém, ou que interessa à sociedade.

\section{REFERÊNCIAS}

ADEODATO, João Maurício. Ética e Retórica: para uma Teoria da Dogmática Jurídica. 5ae ed. São Paulo, SP: Editora Saraiva, 2012.

ARAUJO, Eduardo André Vargas de. Os Poderes do Juiz e o Novo Código de Processo Civil: Estudo sobre Case Management e Flexibilização do Processo. 2015. Disponível em: $<$ https://www.lume.ufrgs.br/bitstream/handle/10183/129816/000976401.p df?sequence=1>. Acesso em: 26 de julho de 2017.

ATAIDE JUNIOR, Vicente de Paula. Processo Civil Pragmático. 2013. 278 f. Tese (Doutorado em Direito das Relações Sociais) - Programa de Pós-Graduação em Direito, Universidade Federal do Paraná, Curitiba, 2013.

BUARQUE DE HOLLANDA, Aurélio. Novo Dicionário Aurélio da Língua Portuguesa. $2^{\mathrm{a}}$ ed. Rio de Janeiro, RJ: Editora Nova Fronteira, 1986.

BRANCO, Paulo Gustavo Gonet. Juízo de Ponderação na Jurisdição Constitucional: Pressupostos de Fato e Teóricos Reveladores de seu Papel e de seus Limites. 2008. 383 f. Tese (Doutorado Constituição, Processo e Teoria Constitucionais, Direitos Fundamentais) - Programa de Doutorado em Direito, Universidade de Brasília, Brasília, 2008.

BUENO, Cassio Scarpinella. Novo Código de Processo Civil Anotado. São Paulo, SP: Editora Saraiva, 2015. 
CABALLERO, Alexandre. A Filosofia através dos Textos. 2ª ed. São Paulo, SP: Editora Cultrix, 1972.

CAMPBELL, James. O Uso Rortyano de Dewey. Trad. Heraldo Aparecido Silva. Redescrições: Revista do GT Pragmatismo e Filosofia Americana, Ano 1, no 2, 2009. Disponível em:

<http://www.gtpragmatismo.com.br/redescricoes/redescricoes/02/2Cam pbell.pdf $>$. Acesso em: 26 de julho de 2017.

D’MACÊDO, Juliana Maria. Pragmatismo Jurídico no Supremo Tribunal Federal. Direito e Humanidades, No. 25, 2013. Disponível em: $<$ http://seer.uscs.edu.br/index.php/revista direito/article/view/2362>. Acesso em: 27 de julho de 2017.

DONIZETTI, Elpídio. A Força dos Precedentes no Novo Código de Processo Civil. 2014. Disponível em:

$<$ http://www9.tjmg.jus.br/data/files/7B/96/D0/66/2BCCB4109195A3B4E8 1808A8/A \%20forca \%20dos\%20precedentes\%20no\%20novo\%20Codigo\% 20de\%20Processo\%20Civil.pdf $>$. Acesso em: 26 de julho de 2017.

ELY, John Hart. Democracia e Desconfiança: Uma Teoria do Controle Judicial de Constitucionalidade. Trad. Juliana Lemos. São Paulo, SP: WMF Martins Fontes, 2010.

GARCIA, André Luis Bitar de Lima; REI, José Anijar Fragoso. O Distinguishing Realizado pelo STF no Julgamento da ADIN 3.421-PR. Revista de Informação Legislativa, Vol. 49, 196, 2012.

GONÇALVES, Daniel Luís Cidade. O Pragmatismo de Richard Rorty e suas Consequências Políticas. Cognitio-Estudos: Revista Eletrônica de Filosofia, Vol. 11, 2, 2014. 
JARDIM, Flávio Jaime de Moraes; PAIVA, Paulo Frederico Rodrigues. Notas acerca de um Processo Civil Pragmático. Revista de Informação Legislativa, Vol. 48, 190, 2011.

LEITE, Glauco Salomão. Inércia Legislativa e Ativismo Judicial: a Dinâmica da Separação dos Poderes na Ordem Constitucional Brasileira. Direito, Estado e Sociedade, No. 45, 2014.

MAUÉS, Antonio Moreira. Jogando com os Precedentes: Regras, Analogias, Princípios. Revista Direito GV, Vol. 8, 2, 2012. Disponível em: $<$ http://direitosp.fgv.br/sites/direitosp.fgv.br/files/artigo-Edicaorevista/09 rev16 587-624 - antonio moreira maues.pdf $>$. Acesso em: 27 de julho de 2017.

NEVES, Daniel Amorim Assumpção. Manual de Direito Processual Civil: Volume Único. 8ª ed. Salvador, BA: Juspodivm, 2016.

OLIVER, Martyn. The Hamlyn History of Philosophy. London: Hamlyn, 1999.

POGREBINSCHI, Thamy. Pragmatismo: Teoria Social e Política. Rio de Janeiro, RJ: Relume Dumará, 2005.

POSNER, Richard. Fronteiras da Teoria do Direito. Trad. Evandro Ferreira e Silva. São Paulo, SP: Editora WMF Martins Fontes, 2011.

RAMOS, Elival da Silva. Ativismo Judicial: Parâmetros Dogmáticos. $2^{\underline{a}}$ ed. São Paulo, SP: Saraiva, 2015.

ROCHA, Maria José Pereira. A Crítica de Richard Rorty à Teoria do Conhecimento e uma Possibilidade de Redescrição. Redescrições: Revista do GT Pragmatismo e Filosofia Americana, Ano 3, 3, 2012. Disponível em: 
$<\underline{\text { http://www.gtpragmatismo.com.br/redescricoes/redescricoes/ano3 03/ }}$ artigo4.pdf $>$. Acesso em: 26 de julho de 2017.

RORTY, Richard. Consequências do Pragmatismo. Trad. João Duarte. Lisboa: Instituto Piaget, 1982.

RUSSELL, Bertrand. The History of Western Philosophy. New York, NY: Touchstone Book, 1972.

SCHAUER, Frederick. Playing by the Rules: a Philosophical Examination of Rule-Based Decision-Making in Law and in Life. Oxford: Clarendon Press, 2002.

TALAMINI, Eduardo. Amicus Curiae no CPC/2015: Amicus curiae comentários ao art. 138 do CPC. In: Teresa Arruda Alvim Wambier; Fredie Didier Jr.; Eduardo Talamini; Bruno Dantas (Orgs.). Breves Comentários ao Novo Código de Processo Civil. São Paulo, SP: Editora Revista dos Tribunais, 2015.

TAVARES, Rodrigo de Souza; BERMAN, José Guilherme. Teorias Dialógicas e os Sistemas de Constituições Não Escritas: o Caso Israelense. Anais do XVIII Congresso Nacional do CONPEDI. Florianópolis, SC: Fundação Boiteux, 2011. Disponível em: $<$ http://www.publicadireito.com.br/conpedi/manaus/arquivos/anais/sao paulo/2259.pdf $>$. Acesso em: 26 de julho de 2017.

WALDRON, Jeremy. A Dignidade da Legislação. Trad. Luís Carlos Borges. São Paulo, SP: Martins Fontes, 2003.

WOOLHANDLER, Ann. Rethinking the Judicial Reception of Legislative Facts. Vanderbilt Law Review, Vol. 41, 111, 1988. 
O Processo Civil Pragmático e o Constitucionalismo Dialógico: Pressupostos para uma Discussão sobre Ativismo Judicial The Pragmatic Civil Procedure and Dialogical Constitutionalism: Assumptions to a Discussion about Judicial Activism Submetido em: 2017-05-15 Aceito em: 2017-08-03 